\title{
Potential for Biomedical Applications of Galactomannans and Xyloglucans from Seeds: An Overview
}

\section{Guilhermina Rodrigues Noleto* and Carmen Lúcia Oliveira Petkowicz}

Departamento de Bioquímica e Biologia Molecular, CP 19046, CEP 81531-980, Universidade Federal do Paraná, Curitiba, Paraná, Brazil

\begin{abstract}
Galactomannans and xyloglucans can be isolated from seeds with relatively high purity and yield; they are water soluble, non-toxic, and biocompatible. These polymers have broad spectra of potential use in medicine, from drug delivery systems to biological response modifiers. The biological activity of polysaccharides is intrinsically linked to their structural aspects. In general the chemical modification of galactomannans and xyloglucans, e.g., sulfation and complexation with oxovanadium, potentiate effects such as cytotoxicity against tumor cells, leishmanicidal activity, and activation of macrophages to release proinflammatory mediators. The wide range of seeds and structural variety favor the isolation of galactomannans and xyloglucans. This allows derivatives to be obtained with targeted properties and activity enabling their use in new applications in the biomedical area.
\end{abstract}

Keywords: Galactomannans; Xyloglucans; Seeds

\section{Introduction}

Seeds play a central role in plant reproduction and human nutrition. A seed contains all the genetic material and nutrients required for the successful propagation of the species. After germination, the reserve material is mobilized to sustain the plantlet before it becomes a selfsufficient autotrophic organism [1,2].

Storage compounds can account for up to $90 \%$ of the seed's dry weight and they are usually responsible for the economic value of seeds $[1,2]$. The main storage compounds accumulated in seeds consist of starch, triacylglycerols, and proteins [1]. Although starch is the most abundant storage carbohydrate, some seeds produce other polysaccharides, which are categorized as reserve compounds [3]. The best studied polysaccharides of this group are galactomannans and xyloglucans. The main reason is the interest due to the economic importance of these polymers, which can be used as thickening and stabilizing agents in the industry $[3,4]$. In addition, as galactomannans and xyloglucans can be isolated from seeds with relatively high purity and yield, are water soluble, non-toxic, and biocompatible, they are also suited for biological applications [5-10].

\section{Galactomannans}

Galactomannans are linear chains of $\beta(1 \rightarrow 4)$ D-mannosyl units, which are substituted by single $\alpha(1 \rightarrow 6)$ linked D-galactopyranosyl residues as side chains. They are usually found in the endosperm of leguminous seeds and the Man/Gal ratio is species specific, typically ranging from 1.1 to $5.0[3,4,11]$. The yield of galactomannan can reach up to $38 \%$ of the seed weight [11]. It has been pointed out that more than 70 species of the family Leguminosae have been identified storing galactomannans [11]. The Man/Gal ratio and the distribution of the galactose units along the main chain strongly affect the functionalities of galactomannans [4]. On the other hand, the relation between Man/ Gal ratio and the biological function of galactomannans has not been established yet [4]. Guar (Cyamopsis tetragonolobus) and locust bean (Ceratonia siliqua) are the main sources of commercial galactomannans, which have Man/Gal ratios of 4:1 and 2:1, respectively. However, several other species have been described to contain galactomannans [11]. Among the alternative sources of galactomannans, Schizolobium amazonicum and Mimosa scabrella seeds have been investigated [3,12].

Regarding the biomedical area, galactomannans have broad spectra of applications, from potential drug delivery systems to biological response modifiers (BRMs) [7,13-18]. The latter ability enables some galactomannans to be used as immunomodulators $[17,18]$. Since galactomannans are heterogeneous and polydisperse polymers [19-21], several studies indicate that applications and effects of galactomannans are intrinsically linked to structural features of the polymers [4]. For example, matrix tablets of galactomannan from Senna tora seeds showed better ability for sustained release potential of losartan potassium when compared to the matrix tablets from other galactomannans, such as that prepared with guar gum [4]. In this regard, chemical modification of galactomannans can be used to improve specific applications [22-27]. Galactomannans extracted from Mimosa scabrella and Leucaena leucocephala seeds, after sulfation protected against infection by flavivirus [23]. Chrestaniet al. [28] also observed antiviral (antiherpectic and antirotavirus) effects by sulfated galactomannan from M. scabrella. Galactomannans from $L$. leucacephala seeds and their chemically sulfated derivative, both at the same concentration, were cytotoxic to HepG2 cells and decreased their viability by $\sim 30 \%$ and $50 \%$, respectively [24]. Chemically sulfated galactomannan from Dimorphandra gardneriana seed was cytotoxic to Vero cells while its unmodified form did not exhibit any effect [25] and the galactomannan from Senna macranthera showed strong anticoagulant activity after sulfation [26].

Galactomannans and their derivatives oxovanadium (IV/V)complexes were evaluated for cytotoxicity against tumor cell lines [29], immunomodulation, and leishmanicidal activities [26]. Native galactomannans (GALMAN-A) isolated from seeds of $M$. scabrella and its enzymatically hydrolyzed form (GALMAN-B), as well as their oxovanadium(IV/V) complexes designated GALMAN-A: $\mathrm{VO}^{2+} / \mathrm{VO}^{3+}$ and GALMANB: $\mathrm{VO}^{2+} / \mathrm{VO}^{3+}$, respectively, were evaluated in $\mathrm{HeLa}$

*Corresponding author: Guilhermina Rodrigues Noleto, Departamento de Bioquímica e Biologia Molecular, CP 19046, CEP 81531-980, Universidade Federal do Paraná, Curitiba, Paraná, Brazil, Tel: +554133611535; E-mail: guinoleto@yahoo.com.br (or) guilherminanoleto@ufpr.br

Received October 18, 2016; Accepted October 26, 2016; Published October 29 2016

Citation: Noleto GR, Petkowicz CLO (2016) Potential for Biomedical Applications of Galactomannans and Xyloglucans from Seeds: An Overview. Med Chem (Los Angeles) 6: 658-661. doi:10.4172/2161-0444.1000411

Copyright: ( 2016 Noleto GR, et al. This is an open-access article distributed under the terms of the Creative Commons Attribution License, which permits unrestricted use, distribution, and reproduction in any medium, provided the original author and source are credited. 
cells [29]. Only the complexed forms promoted cytotoxicity against this cell line and GALMAN-B: $\mathrm{VO}^{2+} / \mathrm{VO}^{3+}$ was $\sim 3$-fold more potent than GALMAN-A: $\mathrm{VO}^{2+} / \mathrm{VO}^{3+}$. In another study, GALMAN-A and GALMAN-A: $\mathrm{VO}^{2+} / \mathrm{VO}^{3+}$ preparations modulated macrophages at different intensities to produce pro-inflammatory mediators [27]. The uncomplexed form increased nitric oxide production by $\sim 33 \%$ compared to control, while GALMAN-A: $\mathrm{VO}^{2+} / \mathrm{VO}^{3+}$ inhibited it. On the other hand, the complexed form increased interleukin-1 beta (IL$1 \beta$ ) and interleukin- 6 (IL-6) by $45 \%$ and $139 \%$, respectively, compared to GALMAN-A. Both preparations, i.e., GALMAN-A and GALMAN$\mathrm{A}: \mathrm{VO}^{2+} / \mathrm{VO}^{3+}$, exhibited leishmanicidal activity against amastigotes of Leishmania (L.) amazonensis and reached $\sim 60 \%$ toxicity. However, GALMAN-A: $\mathrm{VO}^{2+} / \mathrm{VO}^{3+}$ promoted this effect at a four-fold lower concentration than the uncomplexed form. In addition, GALMAN-A and its oxovanadium were three and 12 times more potent, respectively, than Glucantime $(300 \mu \mathrm{g} / \mathrm{mL})$, the main drug used in leishmaniasis treatment. Together, these data indicate that the suitable chemical modification contributes to potentiate the effect of galactomannans.

\section{Xyloglucans}

Storage xyloglucans consist of a cellulose-like backbone carrying single $\alpha$-D-xylopyranosyl units attached to $O-6$, while some xylosyl residues were further substituted at $\mathrm{O}-2$ by $\beta$-D-galactopyranosyl units. They are found in the cotyledons of some leguminous seeds [4]. The content of xyloglucan can reach up to $45 \%$ of the seed [6]. The only commercial source is Tamarindus indica (tamarind). Other leguminous seeds which were described to contain xyloglucans include Copaifera langsdorffi, Hymenaea courbaril, and Mucuna sloanei [6,30]. Xyloglucans from different sources can differ regarding side chain distribution patterns [6].

Xyloglucans possess broad spectra of application in textile, cosmetic, nutritional, and pharmaceutical industries [31]. Regarding the biomedical area, the main use of xyloglucans is in the preparation of formulations for drug delivery system [32-34] due to their capacity to form thermoreversible gels. When galactose units from xyloglucan are partially removed by enzymatic treatment, the modified polymer exhibits thermoreversible gelation in dilute aqueous solutions [35-37]. Due to the relatively low transition temperature of the gels, it is also used in formulations to sustain viscosity and improve application [38]. Tamarind xyloglucan hydrogel scaffolds have also been investigated for neural tissue engineering of the spinal cord [39]. The xyloglucan from $T$. indica seeds is the best studied [40], either in its native or chemically modified forms [41]. As observed for galactomannan, different biological effects of xyloglucans can be achieved by chemical or enzymatic modification of the native polymers. Some biochemical parameters, such as reduction of plasma lipids [42] and inhibition of D-glucose absorption in rats [43], have been observed for oligosaccharides obtained by partial hydrolysis of tamarind xyloglucan. These findings favor their use in formulations as antiobesity agents [31]. Xyloglucan from T. indica with different degrees of sulfation exhibited antiviral activity [44].

Tamarind xyloglucan was used by Bodin et al. [45] to modify cellulose to increase the adhesion of human endothelial cells to tissue while engineering blood vessels. Cao and Ikeda [46] observed that xyloglucan selenious ester and sulfated xyloglucan from Tamarindus indica were active against oxidative damage and tumors. According to those authors, the selenious derivative was more potent than the sulfated one.

Studies with xyloglucans from other seeds have been reported.
Xyloglucan from Tropaeolum majus seeds inhibited the effect of the carcinogen 1-nitropyrene [47]. This effect opens possibilities to add the polymer to food as an antimutagenic agent. Xyloglucans from $C$. langsdorffi (XGC), H. courbaril (XGJ), and M. sloanei (XGM) seeds were evaluated for their biological response modifier capacity [48]. All three xyloglucans increased the number of macrophages in the peritoneal cavity and XGC was 3.3-fold more potent than XGJ to activate macrophages for nitric oxide production. In another study, XGC, XGJ, and xyloglucans from Tamarindus indica (XGT) stimulated mouse peritoneal macrophages to produce IL-1 $\beta$, IL-6, and tumor necrosis factor alpha (TNF- $\alpha$ ), except for XGC, which did not stimulate IL-6 production [49].

Amaral et al. [27] showed that XGJ, as well as its oxovanadium (IV/V) complex (XG):VO), exhibits important leishmanicidal effects. XGJ reduced growth of Leishmania (L.) amazonensis by $59 \%$ compared to the control, while XGJ:VO had a similar effect at 5-fold lower concentration. Additionally, XGJ:VO also increased IL-1 $\beta$ and IL-6 levels by macrophages after the incubation of cells with the complex. Those studies clearly show that the intensity of effects is different for each polymer preparation.

Data from the literature demonstrates that xyloglucans from different seeds can exhibit different biological effects due to differences in the fine structure of polymers. In addition, new biological effects can be achieved by xyloglucan modifications.

\section{Conclusions and Perspectives}

This minireview shows that galactomannans and xyloglucans from seeds can be readily obtained and possess a wide variety of characteristics, from proper physical chemistry properties that enable them to be used as vehicle to drugs to the ability to modify biological responses. Given the broad range of seeds, these polymers can be obtained at higher amounts to be used in broad spectra of applications.

Immunomodulation is used to improve health by preventing and treating many diseases. In recent years, it has been demonstrated that the cure of leishmaniasis can be reached by activating the immune system. Thus, it can be suggested that many activities exhibited by galactomannans and xyloglucans from seeds, such as ability to form gels and their immunomodulating potential, enable them to be used in formulations for topical use in the treatment of diseases such as cutaneous leishmaniasis since local applications can contribute to treatment efficacy. This possibility is in progress in our group.

\section{References}

1. Baud S, Dubreucq B, Miquel M, Rochat C, Lepiniec L (2008) Storage reserve accumulation in Arabidopsis: metabolic and developmental control of seed filling. Arabidopsis Book 6: e0113.

2. Bewley JD, Black M (1986) Seeds germination, structure and composition In: Seeds: Physiology of Developement and Germination. New York: Pleming Press, pp: 1-27.

3. Avigad G, Dey PM (1997) Storage carbohydrates. Plant biochemistry 3: 143-204.

4. Gidley MJ, Reid JG (2006) Galactomannans and other cell wall storage polysaccharides in seeds. Food polysaccharides and their applications 26: 181-215.

5. Persin Z, Stana-Kleinschek K, Foster TJ, Van Dam JE, Boeriu CG, et al. (2011) Challenges and opportunities in polysaccharides research and technology: The EPNOE views for the next decade in the areas of materials, food and health care. Carbohydrate Polymers 84: 22-32.

6. Petkowicz CLO, Vargas-Rechia CG, Busato AP, Reicher F (2006) Carbohidratos em alimentos regionales Iberoamericanos. USP, São Paulo 1: 125-147. 
Citation: Noleto GR, Petkowicz CLO (2016) Potential for Biomedical Applications of Galactomannans and Xyloglucans from Seeds: An Overview. Med Chem (Los Angeles) 6: 658-661. doi:10.4172/2161-0444.1000411

7. Wani SA, Kumar P (2016) Fenugreek: A review on its nutraceutical properties and utilization in various food products. Journal of the Saudi Society of Agricultural Sciences.

8. Nayak AK, Pal D, Santra K (2015) Screening of polysaccharides from tamarind fenugreek and jackfruit seeds as pharmaceutical excipients. Int J Biol Macromol 79: $756-760$

9. Pawar HA, Lalitha KG (2015) Extraction, Characterization, and Molecular Weight Determination of Senna tora (L.) Seed Polysaccharide. Int J Biomater 2015: 928679 .

10. Albuquerque P, Coelho LC, Teixeira JA, Carneiro-da-Cunha MG (2016) Approaches in biotechnological applications of natural polymers. AIMS Molecular Science 3: 386-425.

11. Prajapati VD, Jani GK, Moradiya NG, Randeria NP, Nagar BJ, et al. (2013) Galactomannan: a versatile biodegradable seed polysaccharide. Int $\mathrm{J}$ Biol Macromol 60: 83-92.

12. Ganter JL, Heyraud A, Petkowicz CL, Rinaudo M, Reicher F (1995) Galactomannans from Brazilian seeds: characterization of the oligosaccharides produced by mild acid hydrolysis. Int J Biol Macromol 17: 13-19.

13. Petkowicz CL, Sierakowski MR, Ganter JL, Reicher F (1998) Galactomannans and arabinans from seeds of Caesalpiniaceae. Phytochemistry 49: 737-743.

14. Pawar HA, Lalitha KG (2016) Comparative Study of Sustained Release Potential of a Newly Isolated Senna tora Seed Galactomannan with Commercially Available Polymers. J Bioequiv Availab 8: 015-026.

15. Silveira JL, Bresolin TM (2011) Pharmaceutical use of galactomannans. Química Nova 34: 292-299.

16. Leung MY, Liu C, Koon JC, Fung KP (2006) Polysaccharide biological response modifiers. Immunol Lett 105: 101-114.

17. Santander SP, Aoki M, Hernandez JF, Pombo M, Moins-Teisserenc $\mathrm{H}$, et al (2011) Galactomannan from Caesalpinia spinosa induces phenotypic and functional maturation of human dendritic cells. Int Immunopharmacol 11: 652 660

18. Feng L, Yina J, Niea S, Wana Y, Xie M (2016) Fractionation, physicochemical property and immunological activity of polysaccharides from Cassia obtusifolia. Int J Biol Macromol 91: 946-953

19. Bento JF, Mazzaro I, de Almeida Silva LM, de Azevedo Moreira R, Ferreira ML, et al. (2013) Diverse patterns of cell wall mannan/galactomannan occurrence in seeds of the Leguminosae. Carbohydrate polymers 92: 192-199.

20. Dey PM (1978) Biochemistry of plant galactomannans. Adv Carbohydr Chem Biochem 35: 341-376.

21. Srivastava M, Kapoor VP (2005) Seed galactomannans: an overview. Chem Biodivers 2: 295-317

22. Pires L, Gorin PA, Reicher F, Sierakowski MR (2001) An active heparinoid obtained by sulphation of a galactomannan extracted from the endosperm of Senna macranthera seeds. Carbohydrate polymers 46: 165-169.

23. Ono L, Wollinger W, Rocco I, Coimbra T, Gorin P, et al. (2003) In vitro and in vivo antiviral properties of sulfated galactomannans against yellow fever virus (BeH111 strain) and dengue 1 virus (Hawaii strain). Antivir Res 60: 201-208.

24. Gamal-Eldeen AM, Amer H, Helmy WA, Talaat RM, Ragab H (2007) Chemicallymodified polysaccharide extract derived from Leucaena leucocephala alters Raw 264.7 murine macrophage functions. International immunopharmacology 7: 871-873.

25. Moura Neto E, Sombra VG, Richter AR, Abreu CMWS, Maciel JS, et al (2014) Chemically sulfated galactomannan from Dimorphandra gardneriana seed: Characterization and toxicity evaluation. Carbohydr Polym 101: 1013-1017.

26. Adriazola IO, Evangelista do Amaral A, Amorim JC, Correia BL, Petkowicz $\mathrm{CL}$, et al. (2014) Macrophage activation and leishmanicidal activity by galactomannan and its oxovanadium (IV/V) complex in vitro. J Inorg Biochem 132: 45-51.

27. do Amaral AE, Petkowicz CL, Mercê AL, lacomini M, Martinez GR, et al (2015) Leishmanicidal activity of polysaccharides and their oxovanadium(IV/V) complexes. Eur J Med Chem 90: 732-741.
28. Chrestani F, Sierakowski MR, de Andrade Uchoa DE, Nozawa C, Sassaki GL, et al. (2009) In vitro antiherpetic and antirotaviral activities of a sulfate prepared from Mimosa scabrella galactomannan. International journal of biological macromolecules 45: 453-457.

29. Noleto GR, Petkowicz CLO, Mercê ALR, Noseda MD, Méndez-Sánchez SC, et al. (2009) Two galactomannan preparations from seeds from Mimosa scabrella (bracatinga): Complexation with oxovanadium(IV/V) and cytotoxicity on HeLa cells. J Inorg Biochem 103: 749-757.

30. Teixeira-Sá DM, Reicher F, Braga RC, Beltramini LM, de Azevedo Moreira $R$ (2009) Isolation of a lectin and a galactoxyloglucan from Mucuna sloane seeds. Phytochemistry 70: 1965-1972.

31. Mishra A, Malhotra AV (2009) Tamarind xyloglucan: a polysaccharide with versatile application potential. Journal of Materials Chemistry. J Mater Chem 19: 8528-8536.

32. Sumathi S, Ray AR (2002) Release behaviour of drugs from tamarind seed polysaccharide tablets. J Pharm Pharm Sci 5: 12-18.

33. Chandramouli Y, Firoz S, Vikram A, Mahitha B, Yasmeen BR, et al. (2012) Tamarind seed polysaccharide (tsp) - an adaptable excipient for novel drug delivery systems. Int J Pharm Practice \& Drug Res 2: 57-63.

34. Ganesan K, Rajaram SK, Chinnathambi A, Murugesan V, Muruganantham $\mathrm{K}$, et al. (2013) A sustained release of tablet granules associated with $\mathrm{ZnS}$ nanocrystals using Tamarind seed polysaccharide. J Applied Pharm Sci 3 . S44-S47.

35. Suisha F, Kawasaki N, Miyazaki S, Shirakawa M, Yamatoya K, et al (1998) Xyloglucan gels as sustained release vehicles for the intraperitoneal administration of mytomycin C. Int J Pharm 172: 27-32.

36. Miyazaki S, Suisha F, Kawasaki N, Shirakawa M, Yamatoya K, et al. (1998) Thermally reversible xyloglucan gels as vehicles for rectal drug delivery. Control Release 56: 75-83.

37. Miyazaki S, Suzuki S, Kawasaki N, Endo K, Takahashi A, et al. (2001) In situ gelling xyloglucan formulations for sustained release ocular delivery of pilocarpine hydrochloride. Int J Pharm 229: 29-36.

38. Manchanda R, Arora SC, Manchanda R (2014) Tamarind seed polysaccharide and its modification-versatile pharmaceutical excipients-a review. Int J PharmTech Res 6: 412-420.

39. Nisbet DR, Moses D, Gengenbach TR, Forsythe JS, Finkelstein DI, et al (2009) Enhancing neurite outgrowth from primary neurones and neural stem cells using thermoresponsive hydrogel scaffolds for the repair of spinal cord injury. Journal of Biomedical Materials Research Part A 89: 24-35.

40. Mohamed HA, Mohamed BE, Ahmed KE (2015) Physicochemical Properties of Tamarind (Tamarindus indica) Seed Polysaccharides. J Food Process Technol 6: 6

41. Katiyar N, Malviya R, Sharma PK (2014) Pharmaceutical Applications and Formulation Based Patents of Tamarindus indica Seed Polysaccharide and Their Modified Derivatives. Adv Biol Res 8: 274-281.

42. Yamatoya K, Shirakawa M, Kuwano K, Suzuki J, Mitamura T (1996) Effects of hydrolyzed xyloglucan on lipid metabolism in rats. Food Hydrocol 10: 369-372

43. Sone Y, Makino C, Misaki A (1992) Inhibitory effect of oligosaccharides derived from plant xyloglucan on intestinal glucose absorption in rat. J Nutr Sci Vitaminol 38: 391-395.

44. Mastromarino P, Petruzziello R, Macchia S, Rieti S, Nicoletti R, Orsi N (1997) Antiviral activity of natural and semisynthetic polysaccharides on the early steps of rubella virus infection. J. Antimicrob Chemother 39: 339-345.

45. Bodin A, Ahrenstedt L, Fink H, Brumer H, Risberg B, et al. (2007) Modification of nanocellulose with a xyloglucan-RGD conjugate enhances adhesion and proliferation of endothelial cells: implications for tissue engineering Biomacromolecules 8: 3697-3704

46. Cao Y, Ikeda I (2009) Antioxidant activity and antitumor activity (in vitro) of xyloglucan selenious ester and sulfated xyloglucan. Int $\mathrm{J}$ Biol Macromol 45: 231-235.

47. Hensel A, Meier K (1999) Pectins and xyloglucans exhibit antimutagenic activities against nitroaromatic compounds. Planta Med 65: 395-399. 
Citation: Noleto GR, Petkowicz CLO (2016) Potential for Biomedical Applications of Galactomannans and Xyloglucans from Seeds: An Overview. Med Chem (Los Angeles) 6: 658-661. doi:10.4172/2161-0444.1000411

48. Rosário MM, Noleto GR, Bento JF, Reicher F, Oliveira MB, et al. (2008) Effect of storage xyloglucans on peritoneal macrophages. Phytochemistry 69: 464472.
49. do Rosário MM, Kangussu-Marcolino MM, do Amaral AE, Noleto GR, Petkowicz $\mathrm{CL}$ (2011) Storage xyloglucans: potent macrophages activators. Chem Biol Interact 189: 127-133. 